\title{
Physicist running for president is accused of distorting science to fit guru's ideas
}

Washington. To those who want science to play a larger role in politics, John Hagelin is a reminder that such a development may be a mixed blessing.

Hagelin, a quantum physicist trained at Harvard University, is running for US president as the candidate of the Natural Law Party, whose motto is "bringing the light of science into politics". He and a supporting

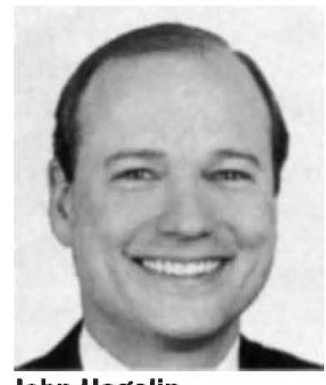

John Hagelin cast of local candidates will appear on the ballot in at least 35 states. (More than 300 people ran unsuccessfully under the party's banner in the British parliamentary election in June.)

$\mathrm{He}$ is by all accounts a gifted scientist, well-known and respected by his colleagues. He is a co-developer of one of the better-accepted unified field theories, known as the flipped SU(5) model. In May, he received an award for young innovators named after Jack Kilby, inventor of the integrated circuit. And his political platform is eminently sensible: practise only those social and economic policies that are supported by scientific data.

However, there is another side of Hagelin that disturbs many researchers. Hagelin is a follower of Maharishi Mahesh Yogi, best known as the guru who taught the Beatles about transcendental meditation (TM), and is on sabbatical from Maharishi International University in Fairfield, Iowa, where students practise mass meditation as a way to ease many of the world's ills, from crime to stress. The home of the Natural Law Party is near the university and most of its members embrace the Maharishi's teachings.

Hagelin has been investigating a scientific mechanism to explain how TM can influence world events. The answer, he believes, lies in extending the grand unified theories of physics to human consciousness.

In the past several years, Hagelin has worked on integrating the SU(5) model, which does not include gravity, into the four-dimensional heterotic superstring model, which is currently considered one of the better prospects for a grand unified 'theory of everything'. Everything, in this case, may even include human consciousness. Two-page advertisements, with row after row of partial differential equations, appear regularly in US newspapers describing how the theoretical physics work of Hagelin and others explains the impact of TM on distant events. Hagelin often lectures on SU(5) and other unified field theories to both scientific and nonscientific audiences, mixed in with a lengthy discussion of TM.

Not surprisingly, the linkage of SU(5) with TM infuriates his former collaborators.

\section{Wellcome Trust to list jobs, grants on line}

London. Job vacancies and funding sources in the biomedical sciences will be available electronically in the spring on a new database to be created by the Wellcome Trust.

The service, to be run from the trust's newly restored Centre for Medical Science in London, will be offered free via the JANET electronic mail system available to most British academic scientists. Although some informal advertising of vacancies already takes place on electronic bulletin boards, the Wellcome Trust's database is thought to be the first formal system on this scale in Britain.

Although the trust expects the jobs database to be self-supporting, the charges will be minimal to enable advertisers to keep positions on the system for longer. Users will be able to access vacancies according to subject, geographical description or any number of hierarchical measures.

The centre's director, Laurence Smaje, said that the charge for a job listing will probably be between $£ 10$ (US\$20) and $£ 20$ per week; by comparison, a quarter-page in Nature costs $£ 600$ and twice that in New Scientist. Although the trust intends to promote the database vigorously, Smaje says that it is not intended to steal business from the weekly magazines and will not promote lectureships and industrial vacancies.

The first step will be to include all vacancies generated by Wellcome Trust or Medical Research Council awards, adding other information as available. While the trust will focus on Britain, organizations elsewhere may also submit material.

Although much of the information on grants is available from libraries, it is largely tied up in a mass of books or on internal databases such as that held by the Association of Medical Research Charities. As well as assembling this information, the grants database will provide such additional facts as the amount of money at a charity's disposal and policies on who may apply.

Ian Mundell
It is hard enough, they complain, to win scientific support for any type of unified theory. "A lot of people [Hagelin] has collaborated with in the past are very upset about this," says Jorge Lopez, a Texas A\&M University physicist. "It's absolutely ludicrous to say that TM has anything to do with flipped SU(5)."

John Ellis, director of CERN's theoretical physics department, has asked Hagelin to stop mixing TM and SU(5). "I was worried about guilt by association," Ellis explains. "I was afraid that people might regard [Hagelin's assertions] as rather flaky, and that might rub off on the theory or on us."

Physicists are not the only scientists to take issue with Hagelin's mix of science and politics. One plank of his party platform calls on presidential candidates to undergo an electroencephalogram (EEG) brain scan that would purport to reveal their neurophysiological qualifications to hold office.

EEG scans, in use since the 1930s, "show the orderliness of the brain", he explains. "Science correlates that to intelligence, creativity, moral stability and broad comprehension." He says that he has had his own brain scanned (he claims an exceedingly orderly brain, in the top 1 per cent of those tested) and will release the results when his competitors do. EEGs, he says, "give us a look under a candidate's hood".

Jonathan Pincus, chairman of the neurology department at Georgetown University in Washington DC, says that researchers once hoped the results of EEG tests might somehow correlate to intellectual qualities. Although EEGs have remained an important tool for spotting neurological disorders, he says, "they have nothing whatsoever to say about a person's moral fibre".

Hagelin himself cites work by E. Roy John, director of the Brain Research Laboratory at the New York University Medical Center, to back his claims. But John says that Hagelin is "overselling" the technique. EEG brain scans have been shown to correlate to "a large number of subtle malfunctions", from senility to substance abuse, he says, "but qualities like moral stability and intelligence are simply not measured".

Even the Kilby award is a bit of a mystery. Few have heard of it, perhaps because it was created three years ago by the North Dallas Chamber of Commerce to draw attention to the area. Truman Cook, a chemical engineer who is a member of the award's executive committee, says that a member of the selection committee who practises TM proposed Hagelin for the award.

Christopher Anderson 